
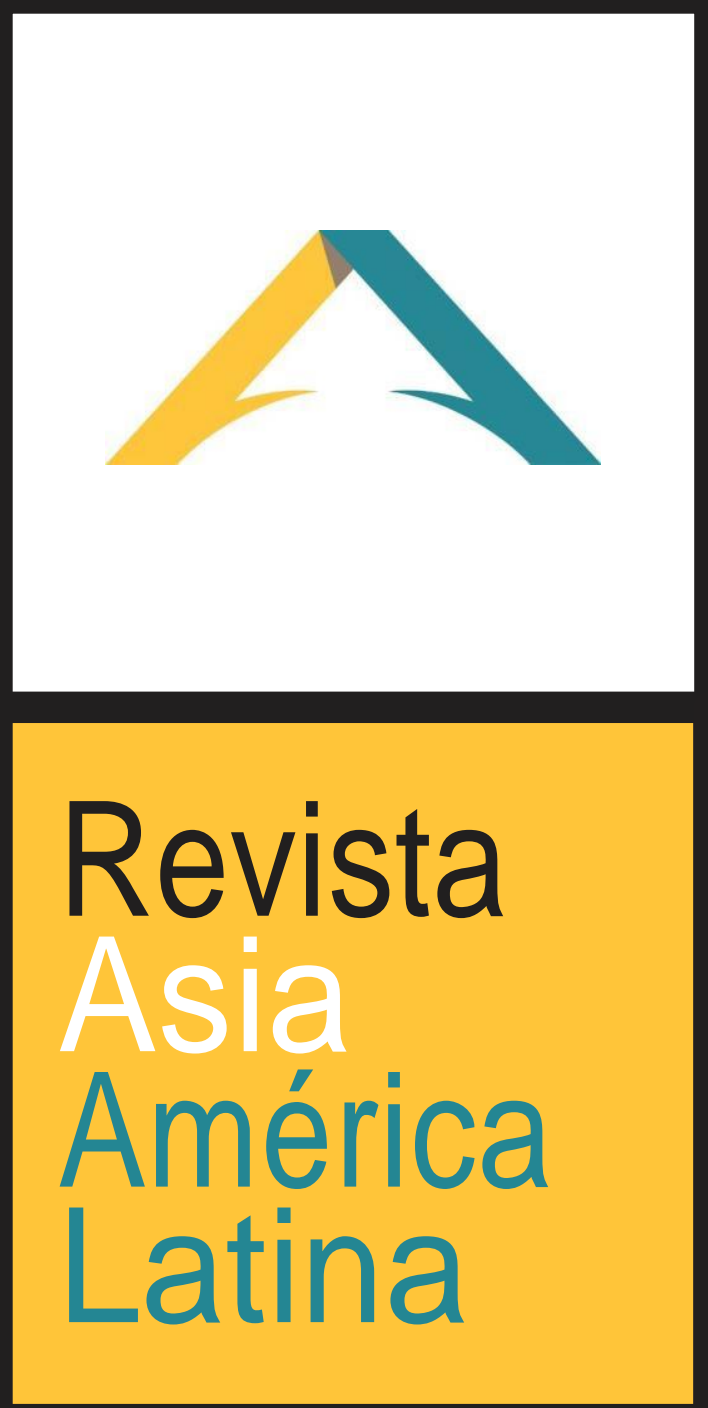

ISSN 2524-9347

Grupo de Estudios sobre Asia y América Latina Instituto de Estudios de América Latina y el Caribe Universidad de Buenos Aires

EU

DE BA 
¿Hacia dónde camina Hong Kong? Movimientos sociales, identidad nacional y el incierto futuro democrático

DANIEL LEMUS-DELGADO Y SALVADOR LEETOY

\section{¿HACIA DÓNDE CAMINA HONG KONG? MOVIMIENTOS SOCIALES, IDENTIDAD NACIONAL Y EL INCIERTO FUTURO DEMOCRÁTICO}

WHERE IS HONG KONG GOING? SOCIAL MOVEMENTS, NATIONAL IDENTITY AND THE UNCERTAIN DEMOCRATIC FUTURE

\section{Daniel Lemus-Delgado}

Instituto Tecnológico y de Estudios Superiores de Monterrey

dlemus@tec.mx

\section{Salvador Leetoy}

Instituto Tecnológico y de Estudios Superiores de Monterrey

sleetoy@tec.mx

Fecha de recepción: 15/07/2020

Fecha de aceptación: 09/02/2021

RESUMEN: Este artículo analiza la narrativa que conecta tres movilizaciones prodemocráticas contemporáneas en Hong Kong a propósito del intervencionismo del Gobierno central chino sobre la Isla. Proponemos que, a pesar de surgir de circunstancias distintas, las tres siguen una misma narrativa de defensa de libertades y derecho a la autodeterminación. Aunque Hong Kong no tiene una experiencia democrática previa, se ha construido un imaginario que hibrida el pasado colonial con la identidad china, y que ha servido de plataforma de resistencia social en contra de intromisiones gubernamentales externas. Así pues, concluimos que las posibilidades democráticas en Hong Kong deben entenderse como un fenómeno rizomático de democracia inconclusa, más que un proceso teleológico con avances y retrocesos, del que seguirán surgiendo nuevas y distintas formas de resistencia de frente a la hegemonía del Gobierno central chino.

PALABRAs Clave: China, Hong Kong, democracia, movimientos sociales, identidad.

ABSTRACT: This article analyzes the narrative connecting three contemporary pro-democracy mobilization in Hong Kong triggered by 
¿Hacia dónde camina Hong Kong? Movimientos sociales, identidad nacional y el incierto futuro democrático

DANIEL LEMUS-DELGADO Y SALVADOR LEETOY

the Chinese Central Government interventionism on the Island. Despite the particularities between each other, we establish that these mobilizations follow a common narrative on defense of liberties and selfdetermination claims. Even though Honk Kong has no previous democratic experience, an imaginary has been held hybridizing its colonial past and Chinese identity, serving as a platform for social resistance against external governmental interference. Accordingly, we state that the erosion of democracy in Hong Kong cannot be entirely understood as a teleology with advancements and backslides. It is instead a rhizomatic phenomenon of an unfinished democracy, from which new and different forms of resistance will continue to emerge facing the hegemony of the Chinese Central Government.

KEY WORDS: China, Hong Kong, democracy, social movements, identity.

\section{Introducción}

La crisis política que sacudió a Hong Kong en el año 2019 pronto obtuvo la atención internacional debido a la continuidad y a la radicalidad de las protestas sociales, dejando al descubierto graves incertidumbres sobre el futuro político de esta Región Administrativa Especial de China (Wai, 2019). Este movimiento inició cuando casi un millón de hongkoneses salieron a las calles el 9 de junio para expresar su repudio al proyecto de ley que autorizaría la extradición de personas sospechas para ser juzgadas en la China continental (Kleefeld, 2019). Desde entonces, se suscitaron múltiples manifestaciones, resultando en no pocas ocasiones en enfrentamientos violentos con la policía y en cada vez un mayor número de actos vandálicos. Al mismo tiempo, la represión policiaca fue en aumento, a pesar de que en aquel momento en Hong Kong las manifestaciones eran consideradas un derecho (Amnistía Internacional, 2019).

Aunque originalmente las protestas comenzaron como un rechazo al proyecto de Ley de Extradición, pronto las demandas se expandieron hasta alcanzar cinco peticiones (Kuo y Yu, 2019). Entre ellas, destacaba la exigencia de realizar una investigación independiente sobre la actuación de la policía durante las manifestaciones (Tara, 2019). A pesar de que el 4 de septiembre la Jefa del Ejecutivo, Carrie Lam anunció el retiro formal del proyecto de Ley de Extradición y dio a conocer otras medidas diseñadas para calmar el descontento general, las manifestaciones continuaron expandiéndose durante las siguientes semanas (Lam, 2019). El gobierno hongkonés impulsó esa nueva ley bajo el argumento que esta permitiría las extradiciones a jurisdicciones con las que Hong Kong no tiene acuerdos al respecto. Para ello tomó el caso de Chan Tong-kai. 
¿Hacia dónde camina Hong Kong? Movimientos sociales, identidad nacional y el incierto futuro democrático

DANIEL LEMUS-DELGADO Y SALVADOR LEETOY

Chan era requerido en Taiwán por el asesinato de su novia Poon Hiu-wing, quien estaba embarazada, ocurrido en Taipei en febrero de 2018, cuando él tenía 20 años. Chan regresó a Hong Kong después de cometer el asesinato y fue encarcelada por delitos relacionados con el lavado de dinero sin poder ser reclamado por el gobierno taiwanés por el crimen cometido en su territorio (Cheung, 2020). Sin embargo, no pocos activistas, como la legisladora Claudia Mo, vieron en el caso "un caballo de Troya" para impulsar una ley que podría ser utilizada en contra los disidentes del sistema político chino limitando las libertades democráticas con las que cuenta el territorio hongkonés (Chan, 2019a).

Las manifestaciones que estallaron son la punta del iceberg de un malestar más grande. Este malestar tiene su origen en una sensación generalizada de pérdida paulatina de autonomía y del respeto a los derechos humanos que se deriva de la política asumida en los últimos años por el gobierno central chino respecto a Hong Kong (Amnistía Internacional, 2019). Esta sensación se ha incrementado a partir del arribo de Xi Jinping a la presidencia de China, quien ha impulsado una política de mayor control social como parte de una estrategia más amplia que implica el rejuvenecimiento de la nación china (Kerr, 2015). En este sentido, es posible sugerir que una parte de la sociedad hongkonesa considera que los logros democráticos alcanzados desde su reincorporación a China están bajo acecho. Desde esta perspectiva, el aumento de la presión derivada de un sistema autoritario como el chino, estaría erosionando los principios y valores democráticos en Hong Kong (Boyajian y Cook, 2019). En consecuencia, las manifestaciones no serían más que la acción colectiva, principalmente jóvenes que se identifican más como hongkoneses que como chinos, de quienes no están dispuestos a abandonar los avances democráticos que esta Región Administrativa Especial ha experimentado desde su retorno a la tutela china en el año 1997 (Albert, 2019).

Paradójicamente, a pesar del dinamismo, los alcances y simpatías que las manifestaciones hongkonesas despertaron tanto en los ciudadanos de la isla como entre miembros de la comunidad internacional, estas manifestaciones generaron, a la postre, un mayor intervencionismo del Partido Comunista Chino que se reflejó en la aprobación de la Ley de Seguridad Nacional. Esta ley fue aprobada el 30 de junio de 2020 por la máxima legislatura de China, la Asamblea Nacional (Yeung, 2020). Esta legislación sin precedentes se redactó en Beijing, se presentó rápidamente a puerta cerrada y se evitó cualquier discusión por parte del poder legislativo local (Tong, 2020). El Secretario de Justicia de la ciudad admitió que la ley no sería compatible con la tradición del derecho consuetudinario de la ciudad, mientras que los críticos argumentaron que las libertades civiles estaban fuertemente restringidas, lo cual significaba el final de la fórmula "Un país, dos sistemas" que había sido el sostén de la reincorporación de Hong Kong a China (Tong, 2020; Hernández, 2020). 


\section{¿Hacia dónde camina Hong Kong? Movimientos sociales, identidad nacional y el incierto futuro democrático \\ DANIEL LEMUS-DELGADO Y SALVADOR LEETOY}

En este sentido, se sugiere que el caso de Hong Kong puede enriquecer la discusión sobre el concepto de democracia, porque se trata de una colectividad que no ha gozado ni de una democracia plena ni de una soberanía real bajo los estándares de la democracia liberal. Bajo la premisa de Erdmann (2011) de que las democracias pueden disminuir en calidad y cambiar a uno de tres tipos de regímenes diferentes -un régimen híbrido, un régimen autoritario o un régimen totalitario-, proponemos, siguiendo a Habermas (1987), que la democracia, como la modernidad, es un proceso inconcluso que debe verse más allá de una visión teleológica. Por lo tanto, las manifestaciones callejeras no son solamente una medida para evitar la degradación de un sistema político que degenere en uno de los posibles escenarios que plantea Erdmann, sino que se trata de la continuación de una lucha por alcanzar una democracia madura como consecuencia de una búsqueda de identidad propia.

Bajo estos supuestos, la pregunta central que guía el presente artículo es si la nueva legislación trastocará las aspiraciones democráticas que han sido un cimiento de la identidad de los jóvenes hongkoneses, quienes encontrarán otras formas de representación y de cohesión social, o, por el contrario, a pesar de la nueva legislación, los movimientos sociales encontrarán nuevas formas creativas en su lucha por alcanzar sus aspiraciones democráticas.

Así, se parte del supuesto de que lo que ahora ocurre en Hong Kong es básicamente la continuidad por concretizar un anhelo democrático, una aspiración de un pasado proyectado e imaginado desde un prisma poscolonial (Leetoy y Lemus-Delgado, 2018). En efecto, se trata de hacer realidad a prácticas democráticas plenas, las cuales jamás se instalaron durante el periodo en que la isla fue una colonia británica. De esta manera, este artículo contribuye a ampliar nuestra comprensión de los procesos sobre las posibilidades democráticas contemporáneas al ampliar el panorama más allá de la visión tradicional de democracia liberal que propone Huntington (1991). Es decir, superar la idea de que la democracia avanza o retrocede en "olas". Al contrario, sugerimos que, en los márgenes de la tradición occidental, presenciamos otros tipos de procesos de democratización. Desde una perspectiva postestructuralista, este artículo propone reflexionar sobre el futuro incierto de Hong Kong a partir de un acercamiento a las dinámicas de autocratización versus democratización desde una perspectiva que amplía paradigmas lineales sobre el desarrollo democrático.

Con la intención de esbozar una respuesta a la pregunta previamente planteada sobre el futuro democrático de Hong Kong, este artículo está organizado en tres secciones. Primero, se examina el caso de las manifestaciones pro-democráticas en Hong Kong. Específicamente, se analizan tres movimientos claves contemporáneos; el movimiento estudiantil de 2011 conocido como Escolarismo en contra de un nuevo currículo que pretendió imponer el Partido Comunista Chino; la llamada Revolución de las Sombrillas de 2014, que se opuso a la reforma electoral que limitaba las candidaturas para 
¿Hacia dónde camina Hong Kong? Movimientos sociales, identidad nacional y el incierto futuro democrático

DANIEL LEMUS-DELGADO Y SALVADOR LEETOY

las elecciones del 2017; y finalmente, las protestas masivas de 2019 en contra de la Ley de Extradición. En la segunda parte, se discuten las posibilidades democráticas a partir del concepto de rizoma, con la intención de ampliar el horizonte interpretativo desde el cual se pueden analizar experiencias democráticas más allá de dinámicas teleológicas. Por último, se concluye que las manifestaciones en Hong Kong siguen una hoja de ruta sustentadas en aspiraciones y anhelos de prácticas democráticas, de las cuales no hay experiencia previa o momento histórico que sirva como hito que demuestre procesos de retroceso o deterioro. Sin embargo, se sostiene que dichas proyecciones son mapas que no necesitan territorio, es decir, exigencias para posibilitar un sistema político más democrático del que nunca se ha gozado, pero que no obstante se presenta como un imaginario operativo para emprender acciones de resistencia. Así, se sugiere que, a pesar de la Ley de Seguridad Nacional, al ser el resultado de un proceso de hibridación cultural, la aspiración democrática del pueblo hongkonés encontrará formas creativas de expresión y manifestación social hasta que se establezcan otros cimientos de la identidad hongkonesa más allá del ideal democrático.

\section{Acciones colectivas en Hong Kong: tres momentos.}

\section{II.1 La oposición a una nueva educación moral y nacional con características chinas}

La búsqueda de la democracia en Hong Kong ha sido un anhelo que se ha incrementado en la última década. Si bien Hong Kong cuenta con una larga tradición de movimientos sociales que se remontan al periodo en que el territorio era aún una colonia británica (Ma, 2009), ahora es posible apreciar nuevas irrupciones cuyo motivo central es garantizar el estatus especial que mantiene Hong Kong en cuanto a su identidad y sus prácticas y valores democráticos (Hofung Hung y Iam-chong Ip, 2012).

En este sentido, uno de este tipo de acciones que desencadenó una extraordinaria movilización estudiantil que se expandió a múltiples sectores de la sociedad hongkonesa, fue la oposición al plan curricular que presentaba una nueva interpretación de la identidad y la historia de Hong Kong (Chan, 2013). Desde la reanudación de la soberanía por parte de China en 1997, el gobierno de Hong Kong ha enfatizado que los ciudadanos de la ciudad se identifiquen con la identidad nacional china (Chong, 2018). Para ello, se ideó esparcir a través de materias específicas, una narrativa sobre la superioridad del sistema político chino (Kaeding, 2015). Así, en el año 2010, el presidente ejecutivo de Hong Kong anunció que la propuesta de un nuevo currículo que impulsara "educación moral y nacional"; para ello, estos contenidos deberían enseñarse como una 
¿Hacia dónde camina Hong Kong? Movimientos sociales, identidad nacional y el incierto futuro democrático

DANIEL LEMUS-DELGADO Y SALVADOR LEETOY

materia independiente en todas las escuelas primarias y secundarias, con la finalidad de cultivar el carácter moral y la identidad nacional (Wang, 2017). Asimismo, se anunció que el nuevo plan se introduciría progresivamente a través de un período de tres años (Chan, 2013). La propuesta tenía un contexto histórico más amplio y se remontaban al menos al año 2007, cuando se diseñó el currículo de Educación Moral y Cívica, generando entonces una amplia controversia porque esta iniciativa fue percibida como un intento de adoctrinar a los estudiantes hongkoneses (Wong y Wright, 2019). En el fondo, el amplio debate suscitado reflejaba la creciente preocupación de la comunidad académica sobre si el pensamiento crítico de los estudiantes se vería afectado (Leung y Yuen, 2012).

En mayo de 2011 se dio a conocer el primer borrador del plan de estudios para su consulta pública (Chow, 2014). Al conocer la iniciativa, un grupo de estudiantes de secundaria pronto formó una organización en contra del nuevo plan curricular, la cual nombraron Scholarism (Bush, 2016). Este grupo estaba compuesto principalmente por jóvenes nacidos en la década de 1990 y que, basándose especialmente en la plataforma Facebook, organizaron protestas masivas contra la iniciativa (Adorjan y Yau Ho Lun, 2015).

Joshua Wong, uno de los fundadores del movimiento, afirmaba que se oponían a la nueva asignatura porque era un intento descarado de adoctrinamiento, ya que, en el borrador de los materiales educativos propuestos, se afirmaba que el Partido Comunista Chino era una "organización progresista, desinteresada y unida", lo que para y él sus compañeros representaba una prueba evidente de un tipo de "lavado de cerebro" que se pretendía hacer con este plan (Veg, 2017).

En la medida en que se alertó a la población hongkonesa de que la nueva asignatura estaba sesgada para generar una imagen propagandista a favor del gobierno chino, pronto se formó una alianza en contra del proyecto de educación moral y nacional. Este movimiento incluyó tanto a grupos recién formados como Scholarism como a grupos con más amplia trayectoria en movilizaciones sociales, entre los que se incluían Parents Concern Group, la Federación de Estudiantes de Hong Kong y el Sindicato de Docentes Profesionales de Hong Kong (Wang, 2017).

La Federación de Estudiantes de Hong Kong fue fundada en el año 1958, originalmente como una organización procomunista organizada por estudiantes universitarios. Antes de la década de 1980, la mayoría de los miembros abogaban por el enfoque idealista y utópico del movimiento comunista en China; sin embargo, el final de la Revolución Cultural en 1976, seguido de la muerte de Mao Zedong, condujo a la desilusión política. En la década de 1980 se organizaron activamente y expresaron las ideas firmes sobre el futuro de Hong Kong después de 1997 y también apoyaron las protestas de los estudiantes de la Plaza Tiananmen en 1989. En la década siguiente, la organización se dedicó 
¿Hacia dónde camina Hong Kong? Movimientos sociales, identidad nacional y el incierto futuro democrático

DANIEL LEMUS-DELGADO Y SALVADOR LEETOY

principalmente a impugnar la violación de derechos civiles y sus miembros participaron activamente en la organización de protestas en algunos de los escándalos clave con relación al gobierno, incluida la intervención oficial del programa de opinión pública en la Universidad de Hong Kong en el año 2000 (Wong y Chung, 2019).

En julio de 2012, más de 90.000 ciudadanos participaron en protestas callejeras para oponerse al lanzamiento de las nuevas asignaturas, y un poco después, más de 8.000 estudiantes universitarios boicotearon las clases, solicitando que la iniciativa se detuviera de inmediato (Chow, 2014). A finales de agosto, miembros de Scholarism organizaron una huelga de hambre y mandaron el mensaje de "Ocupa la Plaza Cívica"; asimismo, se instaló un escenario en la explanada de la sede del gobierno, que los activistas más tarde llamaron "Plaza Cívica" (Wang, 2017). El primero de septiembre, día del nuevo semestre, las organizaciones en contra del nuevo plan curricular llevaron a cabo una nueva manifestación, después de la cual miles de participantes se unieron a la acción de "Ocupa la Plaza Cívica", convirtiendo ese espacio en un lugar para la interacción y debate público, la presentación de conferencias y la búsqueda de apoyo para la causa. El 7 de septiembre de 2012, nuevamente Scholarism logró reunir a 120.000 manifestantes frente a la sede del gobierno (Chow, 2014). Finalmente, el gobierno tuvo que hacer una concesión y suspender el plan de estudios el 8 de septiembre y un día después, la alianza en contra del nuevo plan de estudios se retiró de la Plaza Cívica consiguiendo una importante victoria (Wang, 2017).

\section{II.2 La Revolución de las Sombrillas}

En cierta manera, como continuidad del movimiento de oposición contra la educación moral y nacional, en el año 2014 estalló la llamada Revolución de las Sombrillas. Sin embargo, este movimiento surgió en un contexto caracterizado por el creciente recelo internacional frente a las aspiraciones del gobierno de China continental por garantizar la unidad nacional tanto de Hong Kong como de Taiwán. De hecho, un antecedente de las protestas en Hong Kong se encuentra en la toma en la noche del 18 de marzo de 2014 del Yuan Legislativo de Taiwán por parte un grupo de manifestantes heterogéneos liderados por estudiantes quienes se oponían vehementemente a la aprobación del Acuerdo Comercial de Servicios a través del Estrecho (ACSE) entre China y Taiwán. Ninguno de los estudiantes esperaba que la ocupación, que más tarde se conocería como el Movimiento de Girasoles, engendraría la mayor manifestación de protesta a favor de la democracia en la historia de Taiwán; replantearía el discurso popular sobre la trayectoria política y social que debería seguir la isla y precipitaría meses más tarde la derrota electoral del Kuomintang (KMT), el partido gobernante en ese momento el cual había propuesto un mayor 
¿Hacia dónde camina Hong Kong? Movimientos sociales, identidad nacional y el incierto futuro democrático

DANIEL LEMUS-DELGADO Y SALVADOR LEETOY

acercamiento económico con China (Rowen, 2015). En un movimiento sin precedentes, las acciones de los estudiantes reanimaron a la sociedad civil taiwanesa para que se volcará activa y políticamente en acciones civiles como respuesta a lo que se percibió como un comportamiento antidemocrático por parte de las autoridades gubernamentales. Como parte del movimiento, se llevaron a cabo manifestaciones masivas, además que favoreció un intenso debate sobre la identidad taiwanesa, la toma de decisiones democráticas y la relación que el gobierno de Taipei debía mantener con Beijing (Brindle, 2016).

La llamada Revolución de las sombrillas, que inicialmente fue impulsadas por estudiantes y profesores universitarios, pronto se expandió por diversos puntos de la ciudad alcanzando una difusión inusitada y externando nuevas peticiones que fueron más allá de oponerse a un nuevo plan curricular. Las principales demandas incluían el sufragio universal efectivo para elegir al Jefe Ejecutivo y la reforma constitucional destinada a hacer que el parlamento -el Consejo Legislativo- de Hong Kong fuera más representativo ( $\mathrm{Ng}$ y Fulda, 2018). El estallido de la inconformidad fue el anuncio gubernamental sobre la posibilidad de pre-aprobar a todos los candidatos a Jefe del Ejecutivo (Chang, 2015). Los activistas demandaron que esta disposición no reflejaba la promesa de una amplia autonomía y el derecho al sufragio universal establecida en la Ley Fundamental de Hong Kong (Manero de Lemos, 2019).

El movimiento de las Sombrillas tuvo su origen en el movimiento Occupy Central with Love and Peace (Leetoy y Lemus, 2018). Estas manifestaciones se originaron a partir de la iniciativa del profesor de Derecho en la Universidad de Hong Kong Benny Tai Yiu-ting, emulando el movimiento Occupy Wall Street (Lo, 2013). Al respecto, Yiu-ting sentenció: "Entendemos que China tiene preocupaciones, pero no queremos protestar contra la soberanía china, no somos un movimiento pro independencia ni nada parecido. Tampoco queremos poner a la oposición en el poder; no tenemos intención de ganar el poder. Sólo pedimos cambiar el sistema electoral, que es una petición muy humilde" (Vidal , 2014).

Las tensiones políticas se acrecentaron días después, cuando decenas de miles de personas realizaron una vigilia con velas en conmemoración del 25 aniversario de la represión en la plaza de Tiananmen (Bradsher, 2014). El gobierno central dio un recordatorio contundente a los habitantes de Hong Kong de que las autoridades chinas estaban a cargo de la ciudad. Así, el Consejo de Estado publicó un documento en el que subrayó que el gobierno central tiene un amplio poder para gobernar Hong Kong y estableció que: “...el alto grado de autonomía de la Región Administrativa Especial de Hong Kong no es plena autonomía, ni un poder descentralizado. Es el poder de administrar los asuntos locales según lo autorizado por la dirección central" (Yung, 2014).

En este contexto, ciudadanos organizaron un referéndum sobre el futuro político de Hong Kong en el que participaron más de 780 mil ciudadanos (Chan 
¿Hacia dónde camina Hong Kong? Movimientos sociales, identidad nacional y el incierto futuro democrático

DANIEL LEMUS-DELGADO Y SALVADOR LEETOY

y McKirdy, 2014). La importancia de estas elecciones radica en la manera en que da forma al gobierno de Hong Kong basada en la Ley Básica, la cual es una especie de Carta Magna para este territorio. La Ley Básica protege derechos como la libertad de reunión y la libertad de expresión y también establece la estructura de gobernanza del territorio. El Jefe del Ejecutivo es elegido por un Comité Electoral de 1.200 personas, que a su vez son elegidos por representantes de varios sectores de Hong Kong, quienes representan únicamente el 6\% del electorado. El Jefe del Ejecutivo es designado formalmente para el cargo por el Gobierno Central. Asimismo, el Consejo Legislativo hace y modifica las leyes de Hong Kong. Este está compuesto por 70 miembros, de los cuales 35 escaños son votados directamente en cinco distritos electorales mientras que otros 30 escaños representan "distritos electorales funcionales"; es decir, estos cargos son votados por grupos más pequeños que representan intereses especiales, principalmente empresas, banca y comercio. Históricamente, estos sectores principalmente han sido simpatizantes de las medidas del gobierno Beijing. Los ciudadanos también eligen a cinco concejales de distrito para formar parte de Legislatura. Finalmente, cada uno de los 18 distritos de Hong Kong tiene su propio consejo local, conocidos como consejo de distrito. Estos consejos tienen muy poco poder real y son principalmente órganos consultivos, que actúan como ojos y oídos del gobierno a nivel local, transmitiendo información sobre servicios públicos y cómo se deben usar los fondos. Asimismo, tienen acceso a algunos fondos para gastar en mejoras ambientales o proyectos comunitarios y culturales. Sin embargo, 117 de los concejales de distrito también forman parte del comité que vota por el director ejecutivo, lo que les da potencial para una mayor influencia. Las elecciones tienen lugar cada tres años (BBC, 2019).

Ante la respuesta de las autoridades de que la consulta era "ilegal e inválida", los activistas amenazaron con llevar a cabo una serie de protestas con la intención de interrumpir el distrito de negocios de la ciudad, teniendo en cuenta los principios de desobediencia civil (Forsythe, Buckley y Wong, 2014).

El primer día del mes de julio, una marcha que superó los quinientos mil participantes exigió el derecho al sufragio universal libre y efectivo (Kaiman, 2014a). En agosto, el Comité Permanente de la Asamblea Popular de China dictaminó que los candidatos para el Jefe del Ejecutivo debían ser aprobados por el comité que hasta ese momento se había mostrado leal al gobierno central (Spegele, Yung y Steger, 2014). Aunque la propuesta permitiría las primeras elecciones directas del Jefe del Ejecutivo en la historia de Hong Kong, las posibilidades para elegir al próximo gobernante se limitarían a candidatos previamente aprobados por un comité de nominaciones (Tiezzi, 2014).

Una vez que se anunciaron las nuevas normas para la elección del Jefe del Ejecutivo, Yiu-ting declaró que había comenzado una nueva "era de desobediencia civil” (Silbert, 2014). Así, se convocó a los habitantes de la ciudad 
¿Hacia dónde camina Hong Kong? Movimientos sociales, identidad nacional y el incierto futuro democrático

DANIEL LEMUS-DELGADO Y SALVADOR LEETOY

para que, en caso de que no se implementara el sufragio universal para la elección del Jefe del Ejecutivo en 2017 de acuerdo con las "normas internacionales" de los procesos electorales democráticos, bloquearan caminos y paralizaran el distrito financiero de Hong Kong (Griffiths, 2014).

El primero de octubre, en el 65 aniversario del establecimiento del régimen comunista en China, las manifestaciones contra el gobierno alcanzaron una cifra de cien mil personas (Fan, 2014). El movimiento se radicalizó ante el empuje y determinación de los estudiantes y la ausencia de diálogo por parte de las autoridades. Los manifestantes se fraccionaron en tres grupos que se asentaron en distintos puntos de la ciudad: Admiralty, Mongkok, y Causeway Bay (Wang, 2014). Durante más de dos meses, la ciudad estuvo alterada por las manifestaciones y por los campamentos que los estudiantes colocaron en las calles. Después de más de sesenta días de manifestaciones, los promotores originales de las protestas, Benny Tai, Chan Kin-man y Chi Yiu-ming solicitaron poner fin a las protestas y se entregaron a la policía, al considerar que el movimiento se había alejado del objetivo inicial (Buckley y Wong, 2014). Asimismo, la prolongada ocupación de las calles disminuyó el apoyo popular con el que el movimiento contó en sus orígenes (Wang, 2014). En un artículo periodístico, Benny Tai reconoció: "En la última encuesta realizada por la Universidad de Hong Kong, cerca del 80 por ciento de los encuestados no apoyó la continuación de la ocupación. Eso no quiere decir que el apoyo genuino sufragio universal está en declive pero que más adeptos están cuestionando la eficacia de la prolongación de la ocupación" (Tai, 2014).

El 15 de diciembre la policía desmanteló el último campamento de los manifestantes que quedaba de pie en la ciudad, el de Causeway Bay. Una semana antes, las autoridades habían despejado el sitio principal de las protestas cerca de la sede del gobierno en Admiralty, arrestando a 249 personas, incluyendo una lista de los legisladores prominentes y líderes del movimiento pro democrático. Unas horas más tarde, el Jefe del Ejecutivo Leung declaró que las protestas terminaban de manera oficial (Kaiman, 2014b). Uno de los manifestantes que allí se encontraba, el joven Otto Ng de 18 años de edad, declaró: "Se siente un poco deprimido y sin esperanza, pero al mismo tiempo esto es sólo el comienzo, no es el final... Todavía no hemos conseguido lo que queríamos, pero se despertó a los habitantes de Hong Kong” (Kaiman, 2014b).

\section{II.3 2019: el verano de la radicalidad democrática}

La premonición del despertar de los hongkoneses por parte de jóvenes que participaron en la Revolución de las Sombrillas cristalizó cinco años después, cuando nuevamente los ciudadanos salieron a las calles con la intención de defender su identidad hongkonesa y sus aspiraciones democráticas, así como salvaguardar sus condiciones políticas únicas como hongkoneses y garantizar la 
¿Hacia dónde camina Hong Kong? Movimientos sociales, identidad nacional y el incierto futuro democrático

DANIEL LEMUS-DELGADO Y SALVADOR LEETOY

calidad de vida actuales. El motivo para la movilización fue, en esta ocasión, la oposición a Ley de Extradición propuesta por la Jefa del Ejecutivo, Carrie Lam. Las protestas inicialmente pacíficas, en varias ocasiones alcanzaron al menos un millón de manifestantes, pero con frecuencia estas derivaron en violentos enfrentamientos entre los manifestantes y la policía, creando un ciclo de violencia que el gobierno resultó incapaz de superar mientras que los manifestantes se volvieron más radicales y más dispuestos a participar en actos violentos para lograr sus objetivos.

El 13 de febrero de 2019, el gobierno de Hong Kong anunció una consulta de 20 días para la propuesta de Ley de Legislación de Delincuentes Fugitivos y Asistencia Legal Mutua en Asuntos Criminales, la Ley de Extradición, que permitiría la entrega de personas en el territorio de Hong Kong a las autoridades de la China continental (Liu, 2019). El temor de la promulgación de esta ley era la posibilidad de ampliar el poder de las autoridades continentales para atacar a críticos, activistas de derechos humanos, trabajadores de ONG y cualquier otra persona en Hong Kong y expondría a cualquier hongkonés a eventualmente enfrentar al sistema de justicia de China (Amnistía Internacional, 2019).

Las enmiendas se presentaron formalmente ante el parlamento de Hong Kong el 3 de abril. Sin embargo, ante las protestas sostenidas, Lam anunció el 15 de junio la suspensión de la propuesta sin retirarla por completo del parlamento. Las manifestaciones continuaron desde entonces y las demandas de los participantes incluyeron nuevas peticiones. Entre estas, se encontraban el llevar a cabo una investigación independiente sobre la violencia policial contra los manifestantes, la amnistía para aquellas personas encarceladas a consecuencia de participar en las manifestaciones y la renuncia de la Jefa del Ejecutivo Carrie Lam (Boyajian y Cook, 2019).

Desde entonces, el grito en las calles se tradujo en el lema: "¡Cinco demandas, ni una menos!" (Hui, 2019). Cientos de miles de personas salieron a las calles nuevamente y en las semanas siguientes se presentaron escenas caóticas en el aeropuerto y en las estaciones de metro, a la vez las carreteras y los túneles eran bloqueados repentinamente, causando demoras e inconvenientes para la vida diaria. El 16 de junio más de dos millones de personas marcharon pacíficamente en las calles de Hong Kong de 2019 lo que se considera la manifestación más grande en la historia de Hong Kong (Aministía Internacional, 2019).

En la primera semana de septiembre, después de semanas de protestas, Lam finalmente dijo retiraría indefinidamente el proyecto de ley. En un discurso compartido por la plataforma de internet del gobierno hongkonés, propuso un diálogo a los manifestantes, señalando cuatro acciones concretas para atender las cinco demandas. Específicamente, en cuanto a la última demanda respecto al 
¿Hacia dónde camina Hong Kong? Movimientos sociales, identidad nacional y el incierto futuro democrático

DANIEL LEMUS-DELGADO Y SALVADOR LEETOY

sufragio universal, Cam precisó: “...si queremos lograr esto, las discusiones deben llevarse a cabo dentro del marco legal y en una atmósfera propicia para la confianza y comprensión mutua y sin polarizar aún más a la sociedad" (The Goverment of the Hong Kong Special Administrative Region, 2019). Sin embargo, los manifestantes desconfiaban profundamente de Lam y señalaron que las concesiones eran "demasiado poco" y llegaban "demasiado tarde" (Chan, 2019b). En consecuencia, las manifestaciones continuaron las semanas siguientes. Para entonces, los enfrentamientos entre la policía y los manifestantes se habían vuelto más frecuentes y violentos.

El 1 de octubre, mientras China celebraba los 70 años de gobierno del Partido Comunista, Hong Kong experimentó uno de sus días más violentos y caóticos de su historia. Las manifestaciones comenzaron cuando los manifestantes desafiaron una prohibición policial emprender una marcha por los distritos del centro de la ciudad en la que se coreaba el eslogan del movimiento democrático: “¡Liberen a Hong Kong, revolución de nuestro tiempo!” y se cantaba "Gloria a Hong Kong", una canción que muchos llaman el "himno nacional" (Time, 2019). Los manifestantes se reunieron en al menos una docena de distritos de la ciudad, construyeron barricadas, incendiaron y arrojaron bombas de gasolina y rocas a la policía, quienes respondieron con cargos de porras y gases lacrimógenos. Durante una parte del día, se podía ver el humo de varios incendios sobre el emblemático horizonte de la isla de Hong Kong. Las autoridades dijeron que el saldo había sido 51 personas heridas, incluidas dos en estado crítico y 96 arrestadas (Time, 2019).

Ante este panorama tan complejo, a partir de entonces el gobierno prohibió a los manifestantes el uso de máscaras faciales que eran empleadas para hacer frente a los gases lacrimógenos (Bradsher, Victor y May, 2019). A principios de noviembre, un hombre que aparentemente era partidario de las manifestaciones apuñaló a Junios Ho, un legislador pro Beijing (Ramzy y Yu, 2019). Una semana después, un policía disparó a un manifestante a corta distancia cuando los activistas intentaban establecer un bloqueo de carreteras; más tarde ese día, otro hombre fue incendiado por manifestantes antigubernamentales (Kuo, 2019). Pero tal vez el punto más álgido se presentó ese mismo mes de noviembre, cuando cientos estudiantes se atrincheraron en el campus de la Universidad Politécnica de Hong Kong. Después de dos semanas de ocupar la universidad, en el enfrentamiento con las fuerzas policiacas, unos 800 manifestantes, incluidos 300 menores de 18 años, se habían rendido a las autoridades por la noche, mientras que otros 500 fueron arrestados por disturbios que podrían acarrearles una pena máxima de diez años en la cárcel (Lum y Siu, 2019)

En este clima de creciente tensión, se celebraron elecciones en Hong Kong de consejos locales que fueron vistos como un barómetro de la opinión pública. La votación dio una victoria aplastante para el movimiento 
¿Hacia dónde camina Hong Kong? Movimientos sociales, identidad nacional y el incierto futuro democrático

DANIEL LEMUS-DELGADO Y SALVADOR LEETOY

prodemocrático, con 17 de los 18 consejos ahora controlados por consejeros prodemocráticos, en una poderosa muestra de solidaridad con el movimiento de protesta de la ciudad y una forma de reprender a las autoridades locales por el manejo de la crisis de la ciudad (Graham-Harrison y Yu, 2019). Los resultados de la votación permitieron que 387 de las 452 concejalías fueran para consejeros prodemocráticos. (Graham-Harrison y Yu, 2019). El hecho de que estos nuevos consejeros podrán elegir 117 de los 1200 miembros del comité que selecciona al director ejecutivo de Hong Kong que se realizará se realizará en 2022 va más allá de un respaldo popular al movimiento.

Las protestas que apoyan el movimiento de Hong Kong se extendieron por todo el mundo, con manifestaciones en el Reino Unido, Francia, Estados Unidos, Canadá y Australia. En muchos casos, las personas que apoyaban a los manifestantes se enfrentaron a manifestaciones pro Beijing. Ante esta ola de creciente enojo, el presidente chino, Xi Jinping, advirtió contra el separatismo y dijo que cualquier intento de dividir a China terminaría en "cuerpos destrozados y huesos molidos en polvo" (Perper, 2019). Sin embargo, más efectivas que las palabras de $\mathrm{Xi}$ y de los esfuerzos del gobierno de Lam, las manifestaciones empezaron a perder fuerza debido al inesperado brote del nuevo coronavirus en China continental que redujo notablemente la actividad de los manifestantes y colocó los intereses y preocupaciones de los hongkoneses en otro tema, generando que las posibles nuevas protestas se dirigieran al manejo de la crisis sanitaria (Kirby, 2020). Así, se abría otro paréntesis en la larga marcha hacia la democracia plena en Hong Kong.

\section{Los movimientos sociales y la posibilidad democrática}

"Sé como el agua", rezaba uno de los eslóganes que se escuchaban frecuentemente durante las protestas callejeras que tuvieron lugar el verano de 2019 en Hong Kong. La frase se atribuye a uno de los íconos más importantes de la cultura popular hongkonesa, Bruce Lee. Ésta bien representa las tácticas utilizadas por participantes de las multitudinarias marchas. "Vacía tu mente. Sé amorfo. Moldeable. Como el agua. Ahora que vacías el agua en una taza, se convierte en la taza. La vacías en una botella, se convierte en la botella. La colocas en una tetera, se convierte en la tetera. Ahora el agua puede fluir o puede golpear. Sé como el agua, amigo mío”, decía Lee (Little, 1996). Esta filosofía fue apropiada por los manifestantes para enfrentarse a un orden institucional autoritario: duro como el hielo cuando hay que resistir, escapar como el vapor cuando se está bajo asedio, fluir como el líquido para tomar la ciudad. Así, cada una de las propiedades del agua fue vista como formas de resistencia y de identidad de las movilizaciones. 
¿Hacia dónde camina Hong Kong? Movimientos sociales, identidad nacional y el incierto futuro democrático

DANIEL LEMUS-DELGADO Y SALVADOR LEETOY

Las movilizaciones sociales en la historia reciente de la isla han estado conectadas bajo una narrativa común, la cual se traza en la exigencia para ampliar la vida democrática y la soberanía del pueblo hongkonés, y que surgen de tiempo en tiempo a partir de acciones gubernamentales aparentemente desligadas, pero que guardan una estrecha relación de limitar el derecho a la autodeterminación (Cheung, 2015). La democratización de la vida social y política, o el anhelo de que así sea, fomenta irremediablemente la producción de movimientos sociales conformados por ciudadanos que coinciden en la discusión y defensa de causas vinculantes (Tilly, 2010). Al no ser resueltas dichas causas, los movimientos sociales surgen de manera cíclica, aunque las circunstancias concretas a las que reaccionan cambien en el proceso: puede ser la reacción a una ley fundada en un plan de estudios como el que le dio lugar al movimiento Scholarism en 2011; una iniciativa para pre-aprobar a los candidatos a jefatura del ejecutivo que originó las protestas de la Revolución de las Sombrillas en 2014; o bien, la propuesta de la Ley de Extradición que impulsó las movilizaciones del 2019. Estos momentos muestran la lógica de los movimientos sociales: aparentemente son irrupciones efímeras en el espacio público en contraposición al peligro, percibido o real, de demandar libertades políticas, inexistentes o en formación. No obstante, tienen una periodicidad un tanto caprichosa que es detonada por eventos particulares que tienen un trasfondo común, y que provoca que se manifiesten de manera casi predecible al no solucionarse agravios o demandas provocadas por relaciones de poder (Castells, 2009).

La legitimidad de movimientos sociales y acciones deben, idealmente, partir de lógicas extitucionales para ampliar los horizontes de la democracia. Es decir, deben emanar fuera de espacios de alienación y dominación surgidas de instituciones políticas y económicas, y generarse en su lugar a través de prácticas de ciudadanía participativa desde la esfera pública. Hay que recordar que, de acuerdo a Jürgen Habermas (1984), mientras la lógica del Estado es el poder, y la del mercado es el dinero, la lógica de la esfera pública es la creación de una racionalidad comunicativa. Es decir, se trata de dejar de considerar dinámicas meramente instrumentales de los individuos, en lo particular, para enfocarse a formas de agencia que argumentativamente se contrapongan al poder para la obtención de derechos, a través de la deliberación y actuando de manera colectiva, o más bien conectiva: comunidades y nodos que operan a través de procesos organizacionales que no necesariamente comparten un sentido de unidad a priori, sino que conjuran públicos disímiles, fragmentados o individualizados hacia una causa en común (Bennett y Segerberg, 2013). En ese sentido, las políticas de emancipación que surgen de las movilizaciones en Hong Kong, construyen solidaridades subalternas que hacen, a partir de lo diverso y multitudinario, una forma de imaginario que fluye hacia la construcción de un sentido de identidad común basadas en aspiraciones democráticas. 
¿Hacia dónde camina Hong Kong? Movimientos sociales, identidad nacional y el incierto futuro democrático

DANIEL LEMUS-DELGADO Y SALVADOR LEETOY

La erosión de la democracia se presenta en la actualidad de manera diferente a como sucedía en el siglo XX, cuando los golpes de estado, los autogolpes y el fraude electoral eran escenarios que notoriamente mostraban retrocesos. Ahora, como comenta Nancy Bermeo (2016), esos retrocesos suceden principalmente a través de las instituciones de gobierno que los promotores de la democracia han priorizado, en la forma de golpes de Estado promisorios, engrandecimiento ejecutivo y manipulación electoral estratégica. El primero sucede como una reacción autoritaria ante una crisis, supuestamente temporal, tomada por órganos legalmente establecidos hasta contar con condiciones democráticas normales; el segundo se refiere a la acumulación de poder del ejecutivo para mantener controlada a la oposición; y el tercero explica la manipulación de las elecciones a través del control de los medios y los órganos electorales. En el caso de China, se presenta además un escenario de avances económicos sin necesidad de llevar a cabo reformas democráticas, lo que pone en duda la noción de que la democracia es el único sistema político apropiado para la generación de riqueza y desarrollo (Plattner, 2015), y que sigue una lógica instrumental que restringe la noción de vida buena sólo a condiciones materiales.

Ahora bien, lo que presentan las movilizaciones en Hong Kong es la búsqueda de garantías democráticas. Lógicamente, no hay un precedente de retroceso, pues ni en el pasado colonial ni en el presente semiautónomo, se ha gozado de plena soberanía, sino que es producto de un imaginario poscolonial que, paradójicamente, construye todo un referente de políticas de emancipación. Como apunta Benedict Anderson (2006), una nación es una comunidad política imaginada, e imaginada tanto inherentemente limitada y soberana. En este caso, las formas de identidad van de la mano con exigencias democráticas que buscan impedir una mayor intromisión de la China continental en los asuntos de Hong Kong. El autoritarismo del Gobierno Central erosiona las posibilidades democráticas demandadas por los manifestantes, siendo esto el centro de la discusión: el acotamiento de libertades, la negación de la identidad hongkonesa arraigada en su historia, soberanía, autodeterminación y derechos privados y colectivos, erosionan no sólo la posibilidad de la democracia, sino también de la democracia en su potencialidad como orden rector de una vida social, económica y política propia. Por tanto, es una democracia inconclusa, la cual más que un fin, es el medio para construir su identidad.

Aunque el estatus de Región Administrativa Especial pone a Hong Kong en una circunstancia excepcional sobre ciertas decisiones soberanas, particularmente en el terreno electoral, siguen estando ajustadas al mandato gubernamental chino. No obstante, la democracia en Hong Kong parte de un imaginario colonial al cual, paradójicamente, también se enfrentó: la hoja de ruta institucional del otrora poder colonizador, en tanto nación democrática, se convirtió en experiencia operativa para el desarrollo del sistema político propio. 
¿Hacia dónde camina Hong Kong? Movimientos sociales, identidad nacional y el incierto futuro democrático

DANIEL LEMUS-DELGADO Y SALVADOR LEETOY

La hibridación cultural producto de la experiencia colonial, además de producir significados negativos a través de prácticas de exclusión y discriminación, también reproduce connotaciones positivas de apropiación cultural en la que se generan relaciones fructíferas tanto para el dominante como para el dominado. Esta hibridación, por ejemplo, produce la experiencia imaginada de democracia que opera como mapa en Hong Kong, lo que trasciende connotaciones de imperialismo y dominación del pasado colonial, y que se funde con la identidad china de la isla que sirvió de pegamento, en su momento, para resistir precisamente en contra de esas mismas connotaciones. El significante Reino Unido, por tanto, pospone su significado primero como símbolo de dominación, para luego reconocerse en la propia identidad híbrida de Hong Kong como aspiración democrática. Esta mutua afectación es notoria en el discurso de la ceremonia de traspaso de la soberanía de Hong Kong a China, cuando el Príncipe Carlos dijo que "Gran Bretaña es parte de la historia de Hong Kong y Hong Kong es parte de la historia de Gran Bretaña. También somos parte del futuro uno del otro" (Associated Press, 1997).

Gran Bretaña se convierte así en una cadena de significantes que ahora es apropiado como referente democrático, cuando en otro momento fungió como eje antagonista. Esto, por supuesto, no deja de ser paradójico: en el proceso de hibridación cultural se producen múltiples interpretaciones. Si bien Gran Bretaña fue el poder colonial en el pasado, también es una nación democrática en el presente. Históricamente, su papel imperial resulta anacrónico, símbolo de otro tiempo que no corresponde al orden global actual, pero su sistema democrático contemporáneo se transforma en aspiración política. De la misma manera, la China continental se convierte en ese discurso del pasado que se intenta imponer antagónicamente a una nueva generación de hongkoneses ansiosos de una democracia operativa en la Isla.

Por tanto, la democracia inconclusa en Hong Kong es la construcción de un mapa que precede al territorio, como se pudiera interpretar en línea con el pensamiento de Jean Baudrillard: no existe una experiencia previa de vida democrática, pero las movilizaciones son expresiones sociales de consistencia comunitaria, que aún en la diversidad, construye una identidad imaginada que resiste, una vez más, imposiciones que consideran externas a su condición, fundamentadas en aspiraciones democráticas que nunca se han concretizado plenamente en Hong Kong.

Ahora bien, ante el triunfalismo del fin de la Guerra Fría, Samuel Huntington (1991) propuso que la expansión global contemporánea de la democracia surge a partir de tres momentos históricos que plantea avances y retrocesos. Así, la primera ola democratizadora surge con el derecho al voto de una buena parte de población masculina en los Estados Unidos a partir de 1820 y que se fue ampliando a otros países hasta 1926. La segunda ola democrática surge con la derrota de los regímenes fascistas y el triunfo de los Aliados en la 
¿Hacia dónde camina Hong Kong? Movimientos sociales, identidad nacional y el incierto futuro democrático

DANIEL LEMUS-DELGADO Y SALVADOR LEETOY

Segunda Guerra Mundial. Finalmente, una tercera ola inicia en la década de los 1970 con la caída de los regímenes dictatoriales en Portugal y España. Sin embargo, la visión teleológica de Huntignton no es suficiente, y es más bien limitada para explicar las particularidades en procesos de democratización y sus erosiones en otras regiones del mundo, especialmente en el Sur global. Para el caso de Hong Kong, su condición poscolonial, aunado a la concepción de democracia inconclusa aquí abordada, parece exigir una ruta teórica que contemple una perspectiva postestructuralista para discutir sobre las posibilidades hongkonesas de democracia.

De acuerdo a lo anterior, y basados en Deleuze y Guattari (1987), la democratización más que ser pensada una estructura teleológica, parece pertinente pensarla en términos rizomáticos: una multiplicidad de tradiciones, contextos históricos, prácticas e identidades que se entrecruzan sin contar con una posición absoluta de interpretación, y que solo cobra sentido a partir del complejo ensamblaje que la determina. Al respecto, las olas de Huntington siguen una lógica arbórea, en donde se distinguen las raíces de la expansión del proceso democrático a partir de una perspectiva eurocéntrica sustentada en una idea restringida de progreso: aún con retrocesos, siempre hay una narrativa que asciende a mejores condiciones en el futuro. El problema es que, como el Angelus Novus que diserta Walter Benjamin (2008) en sus Tesis sobre la historia, esto no suele suceder, pues el progreso es también una ilusión que está asentada en la catástrofe.

La democracia es un concepto promiscuo y a menudo puramente retórico (Crick, 2002), que puede ser desvirtuado como discurso de poder para crear dinámicas de exclusión, con la excusa de su defensa o ampliación. Por tanto, el tipo de movimiento social que observamos en Hong Kong parte de discursos que se (re)conectan y (re)apropian de acuerdo al momento histórico del que surgen o, dicho de otra manera, construidos a partir del juego de ideologías que les dan sentido a los imaginarios de ese momento en particular. No siguen una narrativa lineal, sino que conectan discursos culturales (identidad, lenguaje e historia común de una comunidad imaginada), con discursos políticos y sociales (autodeterminación y soberanía para el logro de una democracia plena). Ambos discursos corren en velocidades intermitentes cuyos ecos están presentes en las exigencias de las movilizaciones hongkonesas, que igual aluden a un sentido comunitario de pueblo, y al mismo tiempo se conducen bajo prerrogativas modernas.

Deleuze y Guattari (1987) observaban que, por ejemplo, el Mayo francés de 1968 surgió desde la micropolítica, es decir, de las condiciones locales y la cotidianidad de las clases populares que día a día sienten el pulso de formas de dominación y opresión que las determina. Desde la macropolítica, aquellos que detentan credenciales de expertos tales como funcionarios del gobierno, 
¿Hacia dónde camina Hong Kong? Movimientos sociales, identidad nacional y el incierto futuro democrático

DANIEL LEMUS-DELGADO Y SALVADOR LEETOY

académicos, o la alta burguesía, fallaron en predecir estos acontecimientos, pues las movilizaciones conjugaban distintas identidades que no alcanzaban a comprender. Así también las movilizaciones en Hong Kong, surgen de agravios a una democracia inconclusa bajo condiciones de hibridación poscolonial fuera de la compresión macropolítica. Por tanto, comparte una estructura molecular, como la denominan los autores franceses, que irrumpen a través de un cambio de valores y políticas de emancipación desde la periferia. Pero, en el caso específico de Hong Kong, al mismo tiempo actúan como una forma de argamasa social, al darle sentido a una comunidad imaginada que se sustenta en las aspiraciones por consagrar valores democráticos como forma superior de organización política, los cuales son el resultado del proceso de hibridación cultural previamente señalado.

Así pues, y de manera paradójica, las posibilidades de la democracia en Hong Kong también es un proyecto inconcluso, en la manera que Habermas (1987) define a la modernidad, que si bien es enajenada por esferas de dominación del capitalismo (o capitalismo de Estado como el chino), es un proyecto con potencialidad emancipadora a través del activismo y modos de pensamiento crítico y reflexivo. De hecho, es posible afirmar que la experiencia hongkonesa busca transitar hacia un proyecto de una democracia plural y radical, basado en la lucha por una máxima autonomización de esferas sociales y la multiplicación de espacios políticos en contra de la concentración de poder y conocimiento, tal como lo definen Laclau y Mouffe (2001). El objetivo de radicalizar la democracia es politizar todos los espacios de la vida social, la puesta en marcha de la participación democrática en el espacio público in toto. Por demás interesante resulta, entonces, que las posibilidades democráticas en Hong Kong, surge de un mapa sin territorio que, no obstante, se radicaliza a través de la recuperación del espacio público como locus de lucha hegemónica constituyéndose así en un proceso dialéctico de formación identitaria.

En este contexto, la Ley de Seguridad Nacional representa un desafío mayúsculo para los manifestantes. Esta legislación contempla que los delitos de secesión, subversión, terrorismo y colusión con fuerzas extranjeras se castigan con una pena máxima de cadena perpetua. Además, dañar las instalaciones de transporte público puede considerarse terrorismo y las personas sospechosas de violar la ley pueden ser interceptadas y sometidas a vigilancia. Asimismo, quienes sean declarados culpables no podrán postularse para un cargo público. Por otra parte, el Gobierno Central establecerá una nueva oficina de seguridad en Hong Kong, con su propio personal de aplicación de la ley, ninguno de los cuales quedaría bajo la jurisdicción de la autoridad local y Hong Kong tendrá que establecer su propia comisión de seguridad nacional para hacer cumplir las leyes, con un asesor designado por Beijing. Por último, si la ley entra en conflicto con cualquier ley de Hong Kong, la ley de Beijing tiene prioridad (BBC, 2020). Ante este panorama, ¿puede ser siendo viable que las amplias protestas sociales que 
¿Hacia dónde camina Hong Kong? Movimientos sociales, identidad nacional y el incierto futuro democrático

DANIEL LEMUS-DELGADO Y SALVADOR LEETOY

durante la última década han promovido demandas democráticas pueden continuar? En otras palabras, ¿la nueva legislación trastocará las aspiraciones democráticas que han sido un cimiento de la identidad, principalmente, de los jóvenes hongkoneses?

A partir de lo expuesto, es posible afirmar que, si se parte que la democracia no es un proyecto teleológico y universal, que no se avanza ni se retrocede por olas, las aspiraciones democráticas impulsadas por los recientes movimientos sociales pueden reformularse hacia nuevas demandas y reorientar sus aspiraciones porque existe algo más profundo detrás de las demandas democráticas. La razón fundamental de la aspiración democrática del pueblo hongkonés ha sido no solamente alcanzar un ideal democrático, sino de funcionar como un medio de cohesión social, al proveer una identidad nacional distinta y diferenciada de la identidad del pueblo chino. La democracia no es un fin en sí mismo, sino un medio para fortalecer la pertenencia a una comunidad imaginada que parte de una identidad común compartida, y que es producto de una lectura particular de la historia y un proceso de hibridación cultural. A pesar de que la Ley de Seguridad plantea un escenario hostil a este escenario de autodeterminación, es importante recordar con Foucault (1978) que donde hay poder, hay también resistencia a ese poder, aunque dicha resistencia surja precisamente a partir de la acción de tal poder. Las movilizaciones contemporáneas en Hong Kong surgen como reacción a la hegemonía china sobre la isla, por lo que aún y cuando se agraven las formas de subordinación a las que se les someta, esto mismo provocará que nuevas formas creativas de resistencia vuelvan a surgir.

\section{Conclusiones}

A lo largo de una década, la sociedad hongkonesa ha dado muestra de su disposición para avanzar en una ruta democrática, pasando del reconocimiento a su identidad local, a su propia visión de la historia hasta exigir principios democráticos liberales de alcances más amplios a través del respeto integral hacia la soberanía popular y la celebración de elecciones que respeten el sufragio universal sin condicionamiento. $\mathrm{Al}$ mismo tiempo, las manifestaciones se han vuelto más prologadas, más violentas y divisoras de la propia población de la ciudad. Sin embargo, estas manifestaciones no son una evidencia de una defensa acérrima en contra de una ola de erosión democrática; más bien, es la aspiración y proyección de un anhelo respecto a prácticas democráticas que los hongkoneses nunca han tenido plenamente como consecuencia del proceso de colonización y descolonización.

En este sentido, es posible afirmar que lo que se observa en Hong Kong es una búsqueda constante de una comunidad que se imagina a sí misma como 
¿Hacia dónde camina Hong Kong? Movimientos sociales, identidad nacional y el incierto futuro democrático

DANIEL LEMUS-DELGADO Y SALVADOR LEETOY

democrática. Esta situación se deriva de la doble condición de Hong Kong. Por un lado, su pasado colonial y su transición de régimen político, ya que al dejar de ser una colonia británica no se convirtió en un Estado-nación moderno, sino una organización política particular que goza de amplia autonomía real, pero que depende del Estado chino. Por otro lado, China ha experimentado, desde la llegada del Presidente Xi Jinping al poder, el fortalecimiento de prácticas autoritarias derivadas de un sistema de partido único enmarcada en la idea de que la democracia no es la única ruta al progreso y el desarrollo.

Así, como lo demuestra este caso, los procesos de transición y de erosión democrática en aquellos contextos que se ubican más allá de horizontes de comprensión eurocéntricos, tienen sus propias dinámicas, ritmos, valores y concretizaciones. De esta manera, las particularidades de la ruta democrática hongkonesa deben observarse más allá de teleologías tradicionales, para en su lugar entenderlo desde perspectivas rizomáticas surgidas de la micropolítica (periférica y subalterna). Se trata también de un proceso de transformación virtuoso, pues se arraiga en un ethos social de construcción de identidad común, del cual surge un imaginario en donde ser hongkonés se vuelve sinónimo de ser democrático. Por lo tanto, es posible sugerir que, en el futuro inmediato, las protestas seguirán manifestándose, en diferentes ritmos y escalas, hasta lograr equilibrios temporales entre un auténtico respeto a la identidad y las aspiraciones democráticas.

Quedan pendientes algunas interrogantes que futuras investigaciones podrían abordar. Por ejemplo, hasta dónde estas movilizaciones pueden logran una apertura democrática ante un estado autoritario como el chino, en el que la lógica del capital del orden mundial le otorga un poder planetario. También, en el contexto de la pandemia de COVID-19, cómo un estado de emergencia puede ser la excusa para arrasar contra cualquier acción que se considere en contra del interés nacional. También, será importante investigar cómo, desde la micropolítica, se pueden ampliar otros aspectos de la vida democrática hongkonesa a través de un diseño de política pública que atienda intereses particulares, tales como cuidado del ambiente, libertad de cátedra y de prensa, entre otros. No obstante, lo que sí parece que continuará, serán estas irrupciones constantes de demandas democráticas de cara a posiciones autoritarias.

Así pues, en este contexto, la Ley de Seguridad Nacional podrá limitar momentáneamente el desbordamiento de los movimientos sociales por las duras penalidades que impone. Pero estos movimientos encontrarán formas creativas de expresarse y formas novedosas de protesta social, de la mano de la construcción una identidad hongkonesa concebida a partir de aspiraciones democráticas, y relacionalmente distinta a la de la China Continental. Si algo demuestra la historia de los movimientos sociales, es que las luchas por limitar al poder seguirán surgiendo desde lo molecular, en un proceso inacabado, 
¿Hacia dónde camina Hong Kong? Movimientos sociales, identidad nacional y el incierto futuro democrático

DANIEL LEMUS-DELGADO Y SALVADOR LEETOY

contantemente pospuesto, pero siempre con la mira puesta en la ampliación de la resistencia hacia los poderes establecidos, en una constante búsqueda por alcanzar una identidad colectiva de una comunidad siempre imaginada.

\section{Referencias}

AdORJAN, M. y YAU Ho LUn (2015). "Resinicization and Digital Citizenship in Hong Kong: Youth, Cyberspace, and Claims-Making”. Qualitative Sociology Review, 11(2): 148-162.

Albert, E. (2019). Democracy in Hong Kong. Nueva York: Council on Foreign Relations.

AMnistía InTERnACIONAL (2019). Beijing's "Red Line" In Hong Kong Restrictions on Rights to Peaceful Assembly and Freedom of Expression and Association. Londres: Peter Benenson House.

ANDERSON, B. (2006). Imagined communities. Reflections on the origin and spread of nationalism. Londres: Verso.

Associated PREss (30 de junio de 1997). Hong Kong handover ceremonies. AP.

http://www.aparchive.com/metadata/youtube/8b9c2028866d852e270 f1bc448d5e0f6.

BBC (20 de moviembre de 2019). Hong Kong: What is the Basic Law and how does it work? BBC. https://www.bbc.com/news/world-asia-china49633862\#: : :text $=$ Basic $\% 20$ Law $\% 20$ protects $\% 20$ rights $\% 20$ such,advis ors $\% 2 \mathrm{C} \% 20$ called $\% 20$ the $\% 20$ Executive $\% 20$ Council.

BBC (30 de junio de 2020). Hong Kong security law: What is it and is it worrying? BBC. https://www.bbc.com/news/world-asia-china-

52765838\#: :text=The $\% 20$ new $\% 201$ aw's $\% 20 \mathrm{key} \% 20$ provisions, senten ce $\% 20$ of $\% 20$ life $\% 20$ in $\% 20$ prison\&text $=\operatorname{In} \% 20$ addition $\% 2 \mathrm{C} \% 20$ Hong $\% 20$ Kong $\% 20$ will,with $\% 20 \mathrm{a} \% 20$ Beijing $\% 2$ Dappointed $\% 20$ adviser

Benjamin W. (2008). Tesis sobre la historia y otros fragmentos. Ciudad de México: UACM, Itaca.

BennetT, L. y SEgERBERG, A. (2013). The logic of connective action. Digital media and the personalization of contentious politics. Nueva York: Cambridge University Press.

BERMEO, N. (2016). On democratic backsliding. Journal of Democracy, 27(1): 5-19. doi:10.1353/jod.2016.0012.

Boyajian, A. Y CoOK, S. (2019). Democratic Crisis in Hong Kong: Recommendations for Policymakers. Washington, D.C.: Freedom House.

Bradsher, K. (5 de junio de 2014). Crowds Gather in Hong Kong for Anniversary of Tiananmen Crackdown. New York Times. https://www.nytimes.com/2014/06/05/world/asia/crowds-gather-in- 
¿Hacia dónde camina Hong Kong? Movimientos sociales, identidad nacional y el incierto futuro democrático

DANIEL LEMUS-DELGADO Y SALVADOR LEETOY

hong-kong-to-mark-25th-anniversary-of-tiananmen-killings.html, último acceso, 4 de junio de 2019.

Bradsher, K., Victor, D. y May, T. (4 de octubre de 2019). Hong Kong Banned Masks at Protests. Masked Crowds Protested the Ban. New York Times. https://www.nytimes.com/2019/10/04/world/asia/hong-kongemergency-powers.html.

BRINDLE, A. (2016). A corpus analysis of discursive constructions of the Sunflower Student Movement in the English-language Taiwanese Press. Discourse \& Society, 27(1): 3-19. doi: 10.1177/0957926515605957.

Buckley, C. y Wong A. (4 de diciembre de 2014). Hong Kong Protest Leaders Turn Themselves. The New York Times. https://www.nytimes.com/2014/12/04/world/asia/hong-kongprotests.html.

BusH, R. C. (2016). Hong Kong in the Shadow of China: Living with the Leviathan. Washington, D.C.: Brookings Institution Press.

Castells, M. (2009). Communication Power. Nueva York: Oxford University Press.

CHAn, C. (2013). Young Activists and the Anti-Patriotic Education Movement in Post-Colonial Hong Kong: some insights from Twitter. Citizenship, Social and Economics Education, 12(3): 148-162. doi: http://dx.doi.org/10.2304/csee.2013.12.3.148

Chan, W. y MCKIRDy, E. (24 de junio de 2014). Hong Kong's Occupy Central democracy 'referendum' - What you should know. CNN. http://www.cnn.com/2014/06/24/world/asia/hong-kong-politicsexplainer/

CHAn, H. (4 de septiembre de 2019b). Too little, too late: Hong Kong democrats and protesters vow further action despite extradition bill withdrawal. Hong Kong Free Press. https://www.hongkongfp.com/2019/09/04/littlelate-hong-kong-democrats-protesters-vow-action-despite-extraditionbill-withdrawal/.

CHAn, H. (13 de febrero de 2019a). 'Trojan horse': Hong Kong's China extradition plans may harm city's judicial protections, say democrats. Hong Kong Free Press. https://hongkongfp.com/2019/02/13/trojanhorse-hong-kongs-china-extradition-plans-may-harm-citys-judicialprotections-say-democrats/

Chang, G. (2015). The Hong Kong Moment: Trouble on China's Periphery. World Affairs, 177(5): 9-15.

Cheung, A. (2015). Road to Nowhere: Hong Kong's Democratization. and China's Obligations Under Public International Law. Brooklyn Journal of International Law, 40(2): 467-545.

Cheung, T. (21 de septiembre de 2020). Hong Kong protests: murder suspect at centre of extradition bill crisis will surrender to Taiwan authorities 
¿Hacia dónde camina Hong Kong? Movimientos sociales, identidad nacional y el incierto futuro democrático

DANIEL LEMUS-DELGADO Y SALVADOR LEETOY

'once borders reopen'. South China Morning Press. https://www.scmp.com/news/hong-

kong/politics/article/3102395/hong-kong-protests-murder-suspectcentre-extradition-bill

CHONG, E.K. (2018). \#Nationalistic education in the Hong Kong and the Macao SARs of China". Asian Education and Development Studies, 7(4): 395411. doi:10.1108/AEDS-07-2017-0064

CHOw, A. (2014). Understanding Policy Change: Multiple Streams and National Education Curriculum Policy in Hong Kong. Journal of Public Administration and Governance, 2: 49-64. doi: https://doi.org/10.5296/jpag.v4i2.5184

Crick, B. (2002). Democracy. A very short introduction. Oxford: Oxford University Press.

Deleuze, G. y GuATtari, F. (1987). A thousand plateaus: capitalism and schizophrenia. Minneapolis: University of Minnesota Press.

ErdmanN, G. (2011). Transition from Democracy. Loss of Quality, Hybridisation and Breakdown of Democracy. GIGA Research Programme: Legitimacy and Efficiency of Political Systems, GIGA German Institute of Global and Area Studies. http://repec.gigahamburg.de/pdf/giga 11 wp161 erdmann.pdf.

FAN, J. (1 de octubre de 2014). National Day Dawns on the Hong Kong Protests. The New Yorker. https://www.newyorker.com/news/newsdesk/national-day-dawns-hong-kong-protests.

Forsythe, M., BuCKLEy, C. y Wong, A. (21 de junio de 2014). In Hong Kong, an Unofficial Election Draws Beijing's Ire". The New York Times. https://www.nytimes.com/2014/06/21/world/asia/in-hong-kong-anunofficial-election-draws-beijings-ire.html.

Foucault, M. (1978). The History of Sexuality. Volume 1: An Introduction. Nueva York: Random House.

Graham-HARrison, E. y Yu, V. (24 de noviembre de 2019). Hong Kong voters deliver landslide victory for pro-democracy campaigners. The Guardian. https://www.theguardian.com/world/2019/nov/24/hong-kongresidents-turn-up-for-local-elections-in-record-numbers.

Griffiths, J. (9 de octubre de 2014). How Occupy Central's Democracy Push Turned into an Umbrella Revolution. South China Morning Post. https://www.scmp.com/news/hong-kong/article/1612900/timelinehow-occupy-centrals-democracy-push-turned-umbrella.

HABERMAS, J. (1984) The theory of communicative action. Boston: Beacon Press.

HABERMAS, J. (1987). The philosophical discourse of modernity. Cambridge, MA. MIT Press. 
¿Hacia dónde camina Hong Kong? Movimientos sociales, identidad nacional y el incierto futuro democrático

DANIEL LEMUS-DELGADO Y SALVADOR LEETOY

HernándeZ, J.C. (30 de junio de 2020). Harsh Penalties, Vaguely Defined Crimes: Hong Kong's Security Law Explained. The New York Times. https://www.nytimes.com/2020/06/30/world/asia/hong-kongsecurity-law-explain.html

Ho-fung Hung, e IAM-CHONG Ip. (2012). Hong Kong's Democratic Movement and the Making of China's Offshore Civil Society. Asian Survey, 52(3), 504-527. doi:10.1525/as.2012.52.3.504

Hui, M. (2 de septiembre de 2019). A guide to the most important chants of Hong Kong's protests. Quartz. https://qz.com/1699119/chants-andslogans-of-hong-kongs-protests-explained/.

Huntington, S. (1991). The third wave: Democratization in the late twentieth century. Norman, OK: University of Oklahoma Press.

KaEding, M. P. (2015). Resisting Chinese Influence: Social Movements in Hong Kong and Taiwan. Current History, 114 (773): 210-216. doi: https://doi.org/10.1525/curh.2015.114.773.210

KaImAn, J. (1 de julio de 2014a). "Hong Kong: hundreds of thousands participate in pro-democracy march." The Guardian. https://www.theguardian.com/world/2014/jul/01/hong-kongdemonstration-hundreds-thousands-protest-china.

Kaiman, J. (15 de diciembre de 2014b). "Hong Kong Police Dismantle Final Pro-Democracy Protest Camp". The Guardian. https://www.theguardian.com/world/2014/dec/15/hong-kongpolice-dismantle-final-pro-democracy-protest-camp.

KERR, D. (2015). Conclusion: How Close is China to National Rejuvenation? En D. Kerr (Ed.) China's Many Dreams, (pp. 246-261). Londres: Palgrave Macmillan.

Kirby, J. (2 de febrero de 2020). How Hong Kong's protests are shaping the response to the coronavirus. Vox. https://www.vox.com/2020/2/7/21124157/coronavirus-hong-kongprotests-china-carrie-lam.

KLEEFELD, E. (9 de junio de 2019). Hundreds of thousands attend protest in Hong Kong over extradition bill. Vox. https://www.vox.com/world/2019/6/9/18658650/hong-kongprotest-march-china-extradition-bill-2019.

KuO, L. y YU, V. (10 de junio de 2019). What are the Hong Kong protests about? The

Guardian.

https://www.theguardian.com/world/2019/jun/10/what-are-thehong-kong-protests-about-explainer.

KuO, L. (11 de noviembre de 2019). Hong Kong protests: man shot by police and burns victim in critical condition. The Guardian. https://www.theguardian.com/world/2019/nov/11/hong-kongpolice-shoot-demonstrator-during-morning-rush-hour. 
¿Hacia dónde camina Hong Kong? Movimientos sociales, identidad nacional y el incierto futuro democrático

DANIEL LEMUS-DELGADO Y SALVADOR LEETOY

Laclau, E. y Mouffe, C. (2001). Hegemony and Socialist Strategy: Towards a Radical Democratic Politics. Londres: Verso.

LAM, J. (4 de septiembre de 2019). Five key demands, not one less': Hong Kong protesters make clear that Chief Executive Carrie Lam's bill withdrawal is not enough. South China Morning Post. https://www.scmp.com/news/hong-

kong/politics/article/3025750/five-key-demands-not-one-less-hongkong-protesters-make.

Leetoy, S. y Lemus-Delgado, D. (2018). Hong Kong: Social Imaginaries and Post-Colonial Identities in the Umbrella Revolution. Portes, 12 (23): 119142.

LEung, Y. W. y Yuen, T. W. W. (2012). "Competition between Politicized and Depoliticized Versions of Civic Education Curricula: The Case of Hong Kong". Citizenship, Social and Economics Education 11(1): 45-56. doi:10.2304/csee.2012.11.1.45.

LITTLE, J. (1996). The warrior within: the philosophies of Bruce Lee to better understand the world around you and achieve a rewarding life. Chicago: Contemporary Books.

LIU, N. (10 de junio de 2019). What is Hong Kong's extradition bill?. The Financial Times. https://www.ft.com/content/2063019c-7619-11e9be7d-6d846537acab.

Lo, A. (20 de abril de 2013). How I Occupied Benny Tai's Lunch Hour'. South China Morning Post. http://www.scmp.com/comment/insightopinion/article/1218654/how-i-occupied-benny-tais-lunch-hour.

LuM, A. y SIU, P. (20 de noviembre de 2019). Hong Kong protests: bitter standoff inside Polytechnic University continues with as many as 100 activists still on campus, determined to evade capture. South China Morning Post. https://www.scmp.com/news/hong-

kong/politics/article/3038478/hong-kong-protests-bitter-stand-insidepolytechnic.

MA, N. (2009). Social Movements and State-Society Relationship in Hong Kong. En E. Kuah-Pearce y G. Guiheux (Eds.) Social Movements in China and Hong Kong (pp. 45-64). Amsterdam: Amsterdam University Press.

Manero De Lemos, M. A. (2019). The Basic Laws of Hong Kong and Macau as Internationally Shaped Constitutions of China and the Fall Off of "One Country, Two Systems". Tulane Journal of International \& Comparative Law. 27 (2): 277-338.

NG, N. y FuldA, A. (2012). The Religious Dimension of Hong Kong's Umbrella Movement. Journal of Church \& State, 60 (3): 377-397. doi: $10.1093 / \mathrm{jcs} / \operatorname{csx} 053$. 
¿Hacia dónde camina Hong Kong? Movimientos sociales, identidad nacional y el incierto futuro democrático

DANIEL LEMUS-DELGADO Y SALVADOR LEETOY

PERPER, R. (14 de octubre de 2019). Xi Jinping warns that attempts to divide China will end with 'crushed bodies and shattered bones'"'. Business Insider. https://www.businessinsider.com/xi-jinping-crushed-bodiesshattered-bones-china-hong-kong-2019-10.

Plattiner, M. (2015). Is Democracy in Decline? Journal of Democracy, 26 (1): 510.

RamzY, A. y Yu, E. (5 de noviembre de 2019). "Pro-Beijing Lawmaker Stabbed in Hong Kong". The New York Times. https://www.nytimes.com/2019/11/05/world/asia/junius-hostabbed-hong-kong.html

Rowen, I. (2015). Inside Taiwan's Sunflower Movement: Twenty-Four Days in a Student- Occupied Parliament, and the Future of the Region. The Journal of Asian Studies, 74(1): 5-21. doi:10.1017/S0021911814002174

SilberT, S. (3 de septiembre de 2014). "Hong Kong's Democracy Movement Feels Beijing's Pressure". Los Angeles Times. http://www.latimes.com/world/asia/la-fg-hong-kong-democracyfight-20140903-story.html.

Spegele, B., Yung, C. y STEger, I. (31 de agosto de 2014). Beijing Rules out Open Election in Hong Kong. The Wall Street Journal. https://www.wsj.com/articles/beijing-says-panel-to-name-hong-kongleader-candidates-xinhua-1409472088.

TAI, B. (5 de diciembre de 2014). What Next for Hong Kong?. The New York Times. http://www.nytimes.com/2014/12/05/opinion/benny-tai-onwhy-occupy-central-should-end.html? $\mathrm{r}=0$ \#story-continues-4.

TARA, J. (8 de agosto de 2019). What are the protesters demands? Their five demands listed. CNN Asia Edition. https://edition.cnn.com/2019/08/13/asia/hong-kong-airport-protestexplained-hnk-intl/index.html.

The Goverment of THE Hong Kong Special Administrative Region (2019). Video address by the Chief Executive, Mrs Carrie Lam, to members of the public

today. https://www.info.gov.hk/gia/general/201909/04/P2019090400666.ht $\underline{\mathrm{m}}$.

TiEzZI, S. (29 de Agosto de 2014). "China Drafts Rules for Hong Kong Elections". The Diplomat. https://thediplomat.com/2014/08/chinadrafts-rules-for-hong-kong-elections/.

Tilly, C. (2010). Los movimientos sociales 1768-2008. Desde sus orígenes a Facebook. Barcelona: Crítica.

Time (1 de octubre de 2019). Protester Reported Shot as Hong Kong Marks China's National Day with Widespread Unrest. Time. https://time.com/5689617/hong-kong-protest-china-national-dayoctober-1/. 
¿Hacia dónde camina Hong Kong? Movimientos sociales, identidad nacional y el incierto futuro democrático

DANIEL LEMUS-DELGADO Y SALVADOR LEETOY

Tong, E. (1 de julio de 2020). Explainer: 10 things to know about Hong Kong's national security law - new crimes, procedures and agencies. Hong Kong Free Press. https://hongkongfp.com/2020/07/01/explainer-10-thingsto-know-about-hong-kongs-national-security-law-new-crimesprocedures-and-agencies /

VeG, S. (2017). The Rise of "Localism" and Civic Identity in Post-handover Hong Kong: Questioning the Chinese Nation-state. The China Quarterly, 230: 323-347. doi: https://doi.org/10.1017/S0305741017000571

VIDAL, M. (1 de julio de 2014). El objetivo es lograr una mentalidad democrática. El

País. https://elpais.com/internacional/2014/07/01/actualidad/1404232761 795123.html.

WAI, A. (7 de diciembre de 2019). A city divided: Hong Kong's 6 months of tumultuous protests. Channel News Asia. https://www.channelnewsasia.com/news/asia/hong-kong-protestvoices-six-months-12126226.

WANG, P. (3 de diciembre de 2014). La mutación de la protesta de Hong Kong. El País. https://elpais.com/internacional/2014/12/03/actualidad/1417598073 992852.html.

WANG, K. (2017). Mobilizing resources to the square: Hong Kong's Anti-Moral and National Education movement as precursor to the Umbrella Movement. International Journal of Cultural Studies, 20(2): 127-145. doi: https://doi.org/10.1177/1367877916683796

WonG, W.K.B. y ChUNG, S. (2019). Scholarism and Hong Kong Federation of Students: Comparative Analysis of Their Developments after the Umbrella Movement. Contemporary Chinese Political Economy and Strategic Relations: An International Journal, 2(2): 865-884.

WONG, S.C. y WRIGHT, S. (2019). Hybrid mediation opportunity structure? A case study of Hong Kong's Anti-National Education Movement. New media \& Society. doi: https://doi.org/10.1177/1461444819879509

YeunG, J. (1 de julio de 2020). China has passed a controversial national security law in Hong Kong. Here's what you need to know. CNN. https://edition.cnn.com/2020/06/25/asia/hong-kong-nationalsecurity-law-explainer-intl-hnk-scli/index.html

Yung, C. (10 de junio de 2014). China Reminds Hong Kong of Its Control: Unusual "White Paper" Warning Comes Days After Tiananmen Remembrance. The Wall Street Journal. https://www.wsj.com/articles/china-reminds-hong-kong-of-itscontrol-1402411342. 

